\title{
PENGARUH IKLIM SEKOLAH DAN SUPERVISI AKADEMIK TERHADAP KINERJA GURU SEKOLAH DASAR NEGERI SEKECAMATAN RUMBAI KOTA PEKANBARU
}

\author{
Prioctadebi Nas ${ }^{1)}$ \\ Muhammad Nasir ${ }^{2)}$ \\ Fakhri Ras ${ }^{3)}$ \\ 1) Post Graduate Student of Riau University \\ 2) Lecturer of Education Management Study Programme PPs University of Riau \\ ${ }^{3)}$ Lecturer of Education Management Study Programme PPs University of Riau
}

\begin{abstract}
This study aims to determine the effect school climate on teacher performance, academic supervision of teacher performance, school climate and supervision of academic jointly to teacher performance. Research respondents are elementary school teachers in Rumbai district of Pekanbaru city, amounting to 136 people. Data collection was done through questionnaire as a research instrument. Data analysis used is descriptive analysis, inferential statistical analysis and hypothesis testing. The reliability coefficient of the instrument is calculated using the cronbach alpha formula. The result of the research shows that there is a significant influence between school climate on teacher performance 0,430, and there is significant influence between academic supervision on teacher performance equal to 0,339. While together there is influence of school climate and academic supervision on teacher performance of 0.484.
\end{abstract}

Keywords: School Climate; Academic Supervision; Teacher Performance

\section{PENGARUH IKLIM SEKOLAH DAN SUPERVISI AKADEMIK TERHADAP KINERJA GURU SEKOLAH DASAR NEGERI SEKECAMATAN RUMBAI KOTA PEKANBARU}

\begin{abstract}
ABSTRAK
Penelitian ini bertujuan untuk mengetahui adanya pengaruh iklim sekolah terhadap kinerja guru, supervisi akademik terhadap kinerja guru, iklim sekolah dan supervisi akademik secara bersama-sama terhadap kinerja guru. Responden penelitian adalah Guru Sekolah Dasar di Kecamatan Rumbai Kota Pekanbaru yang berjumlah 136 orang. Pengumpulan data dilakukan melalui penyebaran angket sebagai instrumen penelitian. Analisis data yang digunakan yaitu analisis deskriptif, analisis statistik inferensial dan pengujian hipotesis. Koefisien reliabilitas instrumen dihitung menggunakan rumus alpha cronbach. Hasil penelitian menunjukkan adanya pengaruh signifikan antara iklim sekolah terhadap kinerja guru sebesar 0,430 , dan terdapat pengaruh signifikan antara supervisi akademik terhadap kinerja guru sebesar 0,339. Sedangkan secara bersamasama terdapat pengaruh iklim sekolah dan supervisi akademik terhadap kinerja guru sebesar 0,484 .
\end{abstract}

Kata Kunci: Iklim Sekolah; Supervisi Akademik; Kinerja Guru 


\section{PENDAHULUAN}

Guru dituntut memiliki kinerja yang mampu memberikan dan merealisasikan harapan dan keinginan semua pihak terutama masyarakat umum yang telah mempercayai sekolah dan guru dalam membina anak didik. Secara umum mutu pendidikan yang baik menjadi tolak ukur bagi keberhasilan kinerja yang ditunjukkan guru.

Guru juga memiliki peran yang bertujuan untuk membangun bangsa lewat dunia pendidikan, oleh karena itu perlu adanya guru yang berkualitas dan mempunyai kompetensi yang baik didalamnya. Pada perkembangannya banyak ditemukan guru yang kurang bertanggung jawab sehingga seringkali menimbulkan masalah baik bagi dirinya sendiri ataupun masyarakat. Hal tersebut berdampak pada mutu pendidikan yang bisa dikatakan rendah. Dikarenakan subjek dari pendidikan yaitu guru dan murid belum mempunyai wawasan intelektual yang tinggi. Seorang murid akan mempunyai kualitas intelektual yang rendah apabila guru sebagai pembimbing dalam proses belajar mengajar juga mempunyai kualitas intelektual yang rendah pula.

Masalah rendahnya kinerja guru misalnya masih menjadi permasalahan tersendiri dalam praktek penyelenggaraan pendidikan, apalagi dalam hal pengembangan inovatif seorang guru masih belum banyak ditemukan, padahal dunia pendidikan selalu berkembang dinamis agar mampu memenuhi kebutuhan zaman. Oleh karena itu, sebaiknya optimalisasi pengawasan kepala sekolah melalui supervisi pendidikan harus dilakukan dalam upaya untuk menghindari kejenuhan rutinitas yang cendrung stagnan sehingga tidak ada dinamisasi implementasi proses pendidikan yang pada gilirannya akan mengakibatkan melemahnya kinerja guru.

Kinerja guru akan sangat dipengaruhi oleh keadaan di lingkungan sekitar sekolah, kenyaman seseorang dalam bekerja akan sangat tergantung pada situasi dan kondisi yang ada saat ia bekerja, maka dari itu iklim sekolah yang akan baik dapat menunjang kinerja guru dalam mengajar. Seperti yang dikemukakan oleh Pidarta dalam Saerozi (2005: 2). Ada beberapa faktor yang dapat mempengaruhi kinerja guru dalam melaksanakan tugasnya yaitu: a) Kepemimpinan kepala sekolah; b) Iklim sekolah; c) Harapan-harapan; dan d) Kepercayaan personalia sekolah. Dengan demikian nampaklah bahwa iklim sekolah merupakan salah satu faktor yang akan mempengaruhi kinerja guru.

Menurut Hadiyanto (2004: 176) iklim sekolah adalah situasi atau suasana yang muncul karena adanya hubungan antara kepala sekolah dengan guru, guru dengan guru, guru dengan peserta didik atau hubungan antara peserta didik dengan peserta didik yang menjadi ciri khas sekolah yang ikut mempengaruhi proses belajar mengajar disekolah.

Menurut Mulyasa (2009: 86-88) iklim sekolah harus diciptakan untuk menjawab perubahan-perubahan akibat kemajuan ilmu dan teknologi serta perubahan-perubahan karakteristik pada peserta didik. Perubahan tersebut meliputi beberapa hal berikut : 1) kemajuan ilmu dan pengetahuan yang sangat cepat yang menuntut terciptanya iklim sekolah yang bisa menyesuaikan diri dengan perubahan tersebut; 2) perkembangan penduduk yang cepat membutuhkan layanan pendidikan yang memadai; 3) Kebutuhan akan sumber daya manusia yang berkualitas; 4) perkembangan teknologi informasi yang mempercepat proses komunikasi. 
Dengan terciptanya iklim sekolah yang kondusif, maka guru akan merasa nyaman dalam bekerja dan terpacu untuk bekerja lebih baik. Hal tersebut mencerminkan bahwa suasana sekolah yang kondusif, fasilitas yang lengkap serta kemampuan guru dalam menyesuaikan diri dengan kemajuan teknologi, keilmuan serta pemahaman terhadap karakter murid dan seluruh lapisan sangat mendukung peningkatan kinerja guru.

Ada beberapa faktor yang berpengaruh terhadap meningkatnya kinerja guru, yaitu supervisi yang diberikan oleh kepala sekolah. Supervisi dalam hal ini adalah mengenai persepsi guru terhadap pelaksanaan pembinaan dan bimbingan yang diberikan oleh kepala sekolah yang berdampak kepada kinerja guru yaitu kualitas pengajaran. Agar kualitas pendidikan meningkat maka seorang kepala sekolah harus mampu memberikan supervisi sehingga pengaruhnya dapat menyebabkan guru tergerak untuk melaksanakan tugastugas mulianya secara efektif, sehingga kinerja mereka akan lebih baik.

Berdasarkan hasil pengamatan dan wawancara peneliti di beberapa Sekolah Dasar Negeri di Kecamatan Rumbai Kota Pekanbaru, dapat penulis simpulkan terdapat beberapa fenomena masalah yang menunjukkan rendahnya kinerja guru: 1) Masih terdapat beberapa guru yang belum terampil dalam membuat perencanaan pembelajaran, walaupun ada itu hanya sebatas administratif saja. 2) Dalam pelaksanaan pembelajaran berlangsung tidak efektif, karena guru terpaku pada bahan ajar saja dan tidak bisa mengembangkannya. 3) Kinerja guru kelas terasa terus meningkat dengan adanya pengawasan dan supervisi yang dilaksanakan oleh kelapa sekolah maupun oleh supervisor yang rutin mengawasi terbukti dengan hasil belajar siswa yang terus meningkat dari semester ke semester, tetapi apabila tidak dilakukan supervisi maka gaya mengajar guru kembali seperti semula tidak ada variasi sama sekali. 4) iklim sekolah masih belum menggambarkan suasana dan hubungan kerja yang baik antar sesamanya. Dimana para guru lebih disibukkan dengan aktivitasnya masing-masing, serta masih jarang digelar berbagai even pertemuan yang bisa mendudukkan semuanya secara bersama-sama sehingga diharapkan terjalinnya keakraban. 5) Beberapa guru yang termotivasi dengan sendirinya untuk mengembangkan pribadinya dengan melanjutkan kuliah jejang S2. Namun terdapat pula guru yang masih kurang termotivasi dalam mengembangkan kemampuannya yang masih berjenjang D3, namun jumlahnya tidak begitu banyak ditambah dengan guru yang sudah memasuki masa pensiun. Artinya pengaruh lingkungan sekitar baik orang ataupun kondisi keadaan yang ada akan mempengaruhi individu yang ada dilingkungan tersebut. Disini dapat terlihat bahwa Iklim sekolah memberikan peran tersendiri dalam mempengaruhi guru untuk mengembangkan pribadi.

Pentingnya peranan guru dalam pencapaian tujuan pendidikan juga dikemukakan oleh Ahmad (2003:13) yang menyatakan bahwa "Betapapun baik dan lengkapnya kurikulum, metode, media, sumber, sarana dan prasarana, namun keberhasilan pendidikan terletak pada kinerja guru". Menurut Usman (2005:7) : "Guru yang kompeten akan lebih mampu menciptakan lingkungan belajar yang efektif dan akan lebih mampu mengelola kelasnya sehingga hasil belajar siswa berada pada tingkat optimal".

Berdasarkan latar belakang masalah, identifikasi masalah, dan 
pembatasan masalah yang telah diuraikan diatas, maka dapat dirumuskan permasalahan dalam penelitian ini sebagai berikut:

1. Apakah terdapat pengaruh iklim sekolah terhadap kinerja guru Sekolah Dasar Negeri seKecamatan Rumbai Kota Pekanbaru?

2. Apakah terdapat pengaruh supervisi akademik terhadap kinerja guru Sekolah Dasar Negeri seKecamatan Rumbai Kota Pekanbaru?

3. Apakah terdapat pengaruh iklim sekolah dan supervisi akademik secara bersama-sama terhadap kinerja guru Sekolah Dasar Negeri seKecamatan Rumbai Kota Pekanbaru?

\section{METODOLOGI PENELITIAN}

Penelitian ini menguji tiga variabel yang akan diteliti dan untuk mengetahui ada tidaknya pengaruh antara variabel independen dengan variabel dependen. Sehubungan dengan ini maka yang menjadi variabel $\mathrm{X}_{1}$ (independen) adalah iklim sekolah, variabel $\mathrm{X}_{2}$ (independen) adalah supervisi akademik dan variabel $\mathrm{Y}$ (dependen) adalah kinerja guru.

Populasi dalam penelitian ini adalah guru Sekolah Dasar Negeri seKecamatan Rumbai Kota Pekanbaru yang berjumlah 101 guru dari 136 orang guru yang tersebar di 13 sekolah Dasar Negeri di Kecamatan Rumbai Kota Pekanbaru.

Untuk lebih jelasnya, deskripsi data penelitian kinerja guru dapat dilihat pada tabel 4.1:

Tabel 4.1. Distribusi Frekuensi Skor Kinerja Guru (Y)

\begin{tabular}{|c|c|c|c|}
\hline \multirow{2}{*}{ Kategori } & \multirow{2}{*}{ Kelas Interval } & \multicolumn{2}{|c|}{ Frekuensi } \\
\cline { 3 - 4 } & $95-101$ & 2 & Absolut \\
\hline Sangat Tinggi & $88-94$ & 4 & 1,98 \\
\hline Tinggi & $80-87$ & 41 & 3,96 \\
\hline Sedang & $72-79$ & 40 & 40,59 \\
\hline Rendah & $63-71$ & 14 & 13,6 \\
\hline Sangat Rendah & & 101 & 100 \\
\hline \multicolumn{2}{|c|}{ Jumlah }
\end{tabular}

Teknik pengumpulan data adalah angket. Angket merupakan teknik pengumpulan data yang dilakukan dengan cara memberi seperangkat pertanyaan atau pernyataan tertulis kepada responden untuk dijawab. Angket dalam penelitian ini terdiri dari butir pernyataan yang terkait dengan iklim sekolah, supervisi akademik dan kinerja guru.

Teknik yang digunakan dalam analisis data adalah analisis statistik deskriptif dan analisis statistik inferensial.

\section{HASIL PENELITIAN DAN PEMBAHASAN \\ 1. Data Kinerja Guru (Y)}

Deskriptif merupakan suatu cara menggambarkan persoalan yang berdasarkan data yang dimiliki yakni dengan cara menata data tersebut sedemikian rupa sehingga dengan mudah dapat dipahami tentang karakteristik data, dijelaskan dan berguna untuk keperluan selanjutnya. Berdasarkan hasil perhitungan terhadap data kinerja guru diperoleh skor empiris terendah yang dicapai responden adalah 63 dan skor tertinggi adalah 101 dengan rentang sebesar 38. Perhitungan terhadap distribusi skor tersebut adalah: (1) skor rata-rata $=79,16 ;(2)$ simpangan baku = 6,682; (3) median $=79$; dan (4) modus $=76$. yang digunakan dalam penelitian ini 
Berdasarkan tabel 4.1 diketahui distribusi frekuensi skor kinerja guru terdiri dari lima kelas interval. Skor tertinggi kinerja guru terdapat pada interval $80-87$ sebanyak 41 orang atau 40,59\%. Dengan demikian skor kinerja guru Sekolah Dasar Negeri seKecamatan Rumbai Kota Pekanbaru berada dalam kategori sedang.

\section{Data Iklim Sekolah $\left(\mathrm{X}_{1}\right)$}

Untuk lebih jelasnya, deskripsi data penelitian tentang iklim sekolah dapat dilihat pada tabel 4.2 :

Tabel 4.2. Distribusi Frekuensi Skor Iklim Sekolah $\left(\mathrm{X}_{1}\right)$

\begin{tabular}{|c|c|c|c|}
\hline \multirow[b]{2}{*}{ Kategori } & \multirow[b]{2}{*}{ Kelas Interval } & \multicolumn{2}{|c|}{ Frekuensi } \\
\hline & & Absolut & Relatif (\%) \\
\hline Sangat Baik & $73-77$ & 6 & 5,94 \\
\hline Baik & $69-72$ & 17 & 16,83 \\
\hline Sedang & $62-67$ & 40 & 39,6 \\
\hline Tidak Baik & $56-61$ & 30 & 29,7 \\
\hline Sangat Tidak Baik & $50-55$ & 8 & 7,92 \\
\hline \multicolumn{2}{|c|}{ Jumlah } & 101 & 100 \\
\hline
\end{tabular}

Berdasarkan tabel 4.4 diketahui distribusi frekuensi skor iklim sekolah terdiri dari lima kelas interval. Skor tertinggi iklim sekolah terdapat pada interval 62-67 sebanyak 40 orang atau $39,6 \%$. Dengan demikian skor iklim sekolah Sekolah Dasar Negeri seKecamatan Rumbai Kota Pekanbaru berada dalam kategori sedang.

\section{Data Supervisi Akademik $\left(\mathbf{X}_{2}\right)$}

Tabel 4.3. Distribusi Frekuensi supervisi akademik $\left(\mathrm{X}_{2}\right)$

\begin{tabular}{|c|c|c|c|}
\hline \multirow[b]{2}{*}{ Kategori } & \multirow[b]{2}{*}{ Kelas Interval } & \multicolumn{2}{|c|}{ Frekuensi } \\
\hline & & Absolut & Relatif (\%) \\
\hline Sangat Tinggi & $79-84$ & 6 & 5,94 \\
\hline Tinggi & $72-78$ & 30 & 29,7 \\
\hline Sedang & $65-71$ & 35 & 34,65 \\
\hline Rendah & $59-64$ & 24 & 23,76 \\
\hline Sangat Rendah & $53-58$ & 6 & 5,94 \\
\hline \multicolumn{2}{|c|}{ Jumlah } & 101 & 100 \\
\hline
\end{tabular}

terhadap data iklim sekolah diperoleh skor empiris terendah yang dicapai responden adalah 50 dan skor tertinggi adalah 77 dengan rentang sebesar 27. Perhitungan terhadap distribusi skor tersebut adalah : (1) skor rata-rata = 63,019 ; (2) simpangan baku $=5,964$; (3) median $=63$; dan (4) modus $=63$. Untuk lebih jelasnya, deskripsi data penelitian tentang iklim sekolah dapat dilihat pada tabel 4.2: 
Berdasarkan tabel 4.6 diketahui distribusi frekuensi skor supervisi akademik terdiri dari lima kelas interval. Skor tertinggi supervisi akademik terdapat pada interval 65-71 sebanyak 35 orang atau 34,65\%. Dengan demikian skor supervisi akademik Sekolah Dasar Negeri seKecamatan Rumbai Kota Pekanbaru berada dalam kategori sedang.

\section{Pengujian Persyaratan Analisis}

Analisa data untuk menguji hipotesis penelitian yang dilakukan dengan menggunakan analisis statistik parametrik yaitu analisis regresi

Tabel 4.4 Pengujian Normalitas Iklim Sekolah, Supervisi Akademik dan Kinerja Guru

\section{Tests of Normality}

\begin{tabular}{|l|r|r|r|}
\hline \multirow{2}{*}{} & \multicolumn{3}{|c|}{ Kolmogorov-Smirnov $^{\mathrm{a}}$} \\
\cline { 2 - 4 } & Statistic & \multicolumn{1}{c|}{ df } & \multicolumn{1}{c|}{ Sig. } \\
\hline Kinerja_Guru_Y & .051 & 101 & $.200^{*}$ \\
Iklim_Sekolah_X1 & .073 & 101 & $.200^{*}$ \\
Supervisi_Akademik_X2 & .084 & 101 & .079 \\
\hline
\end{tabular}

Hasil pengujian normalitas di atas menunjukkan bahwa Sig pada tabel Kolmogorov-Smirnov $\quad(0,200, \quad 0,200$, $0,079>0,05$ hal ini berarti bahwa pada taraf signifikans $\alpha=0.05$ data penelitian berasal dari populasi yang berdistribusi normal, sehingga memenuhi persyaratan pengujian korelasi dan regresi.

\section{Pembahasan}

Pengujian hipotesis dalam penelitian ini bertujuan untuk menguji tiga hipotesis yang telah dirumuskan yaitu: (1) Pengaruh iklim sekolah (X1) sederhana dan ganda. Pengujian persyaratan analisis ini menggunakan uji normalitas.

\section{Uji Normalitas}

Uji normalitas data pada penelitian ini menggunakan uji Kolmogorov-Smirnov, dengan taraf signifikansi yang digunakan sebagai aturan untuk menerima atau menolak pengujian normalitas atau ada tidaknya suatu distribusi data $\alpha=0,05$.

Untuk melihat uji normalitas kinerja guru, iklim sekolah dan supervisi akademik dapat di lihat pada Tabel 4.4

\section{Tabel 4.5. Uji regresi Linier Iklim Sekolah $\left(\mathrm{X}_{1}\right)$ terhadap Kinerja Guru (Y)}

\begin{tabular}{|c|c|c|c|}
\hline Model & B & $t_{\text {hitung }}$ & $t_{\text {tabel }}$ \\
\hline (Konstan) & 32,874 & 6,109 & \multirow{2}{*}{1,660} \\
\hline Iklim Sekolah & 0,735 & 8,640 & \\
\hline
\end{tabular}


Hasil uji keberartian regresi dapat dilihat berdasarkan persamaan regresi sebagai berikut:

$$
\begin{aligned}
& \mathrm{Y}=\mathrm{a}+\mathrm{bx} \\
& \mathrm{Y}=32,874+0,735 \mathrm{X}_{1}
\end{aligned}
$$

Berdasarkan persamaan di atas dapat diartikan bahwa konstanta sebesar 32,874, artinya jika iklim sekolah (X1) nilainya 0 , maka pengaruh terhadap kinerja guru (Y) nilainya sebesar 32,874. Koefisien regresi variabel iklim sekolah (X1) sebesar 0,735, berarti jika nilai iklim sekolah (X1) mengalami kenaikan 1 satuan, maka nilai tingkat kinerja guru (Y) akan mengalami kenaikan sebesar 0,735. Koefisien bernilai positif artinya terjadi pengaruh positif nilai iklim sekolah (X1) terhadap kinerja guru (Y). Semakin tinggi nilai iklim sekolah (X1) maka semakin meningkat pula tingkat kinerja guru (Y).

Tingkat signifikasi menggunakan 0,05. Berdasarkan tabel $4.11 \mathrm{di}$ atas diperoleh t hitung sebesar 8,640 . Tabel distribusi t dicari pada $\alpha=$

Tabel 4.6 Uji regresi Linier Supervisi Akademik $\left(\mathrm{X}_{2}\right)$ dengan Kinerja Guru (Y)

\begin{tabular}{|c|c|c|c|}
\hline Model & $\mathrm{B}$ & $\mathrm{t}_{\text {hitung }}$ & $\mathrm{t}_{\text {tabel }}$ \\
\hline (Konstan) & 39,603 & 7,101 & \multirow{2}{*}{1,660} \\
\hline Supervisi Akademik & 0,579 & 7,128 & \\
\hline
\end{tabular}

Berdasarkan persamaan di atas dapat diartikan bahwa konstanta sebesar 39,603 ini artinya jika supervisi akademik (X2) nilainya 0 , maka kinerja guru (Y) nilainya sebesar 39,603. Koefisien regresi variabel supervisi akademik (X2) sebesar 0,579, ini berarti jika nilai supervisi akademik (X2) mengalami kenaikan 1 satuan, maka nilai kinerja guru (Y) akan mengalami kenaikan sebesar 0,579. Koefisien bernilai positif artinya terjadi pengaruh positif nilai supervisi akademik (X2) terhadap kinerja guru (Y). Semakin
$5 \%: 2=2,5 \%$ (uji 2 sisi) dengan derajat kebebasan (df) n-k-1 atau 101-2-1 = 98 dengan pengujian dua sisi (signifikasi $=$ $0,05)$ hasil diperoleh $t$ tabel sebesar 1,660 .

Berdasarkan pembahasan di atas dapat disimpulkan bahwa nilai t hitung $>\mathrm{t}$ tabel $(8,640>1,660)$ maka $\mathrm{Ha}$ diterima, artinya bahwa terdapat pengaruh yang signifikan iklim sekolah (X1) terhadap kinerja guru (Y). Jadi, dapat disimpulkan bahwa iklim sekolah (X1) berpengaruh terhadap kinerja guru (Y) Sekolah Dasar Negeri seKecamatan Rumbai Kota Pekanbaru.

\subsection{Pengaruh Supervisi Akademik (X2) terhadap Kinerja Guru (Y)}

Setelah dilakukan pengujian persyaratan analisis, selanjutnya dilakukan uji korelasi dan untuk uji regersi disajikan pada Tabel 4.6 : tinggi nilai supervisi akademik (X2) maka semakin meningkat kinerja guru (Y).

Pada tingkat signifikasi menggunakan 0,05 , jumlah $\mathrm{t}$ hitung dapat dilihat pada tabel 4.15 di atas yaitu sebesar 7,128. Menentukan tabel distribusi $\mathrm{t}$ dicari pada $\alpha=5 \%: 2=$ $2,5 \%$ (uji 2 sisi) dengan derajat kebebasan (df) n-k-1 atau 101-2-1 = 98 dengan pengujian dua sisi (signifikansi $=0,05)$ hasil diperoleh untuk t tabel sebesar 1,660. 
Berdasarkan pembahasan di atas dapat diambil kesimpulan bahwa nilai $\mathrm{t}$ hitung > t tabel $(7,128>1,660)$ maka Ha diterima, artinya bahwa ada pengaruh supervisi akademik (X2) terhadap kinerja guru (Y). Jadi dapat disimpulkan bahwa supervisi akademik (X2) berpengaruh terhadap kinerja guru (Y) Sekolah Dasar Negeri seKecamatan Rumbai Kota Pekanbaru.

Tabel 4.7. Koefisien Regresi Linier Iklim Sekolah $\left(\mathrm{X}_{1}\right)$ dan Supervisi Akademik $\left(\mathrm{X}_{2}\right)$ terhadap Kinerja Guru (Y)

\begin{tabular}{|c|c|c|c|}
\hline Model & B & $t_{\text {hitung }}$ & \multirow{2}{*}{$t_{\text {tabel }}$} \\
\hline (Konstan) & 25,463 & 4,519 & \multirow{2}{*}{1,660} \\
\hline Iklim Sekolah & 0,536 & 5,256 & \\
\hline Supervisi Akademik & 0,291 & 3,221 & \\
\hline
\end{tabular}

Berdasarkan persamaan di atas dapat disimpulkan konstanta sebesar 25,463, artinya jika iklim sekolah $\left(\mathrm{X}_{1}\right)$ dan supervisi akademik (X2) nilainya 0 , maka tingkat kinerja guru (Y) nilainya adalah 25,463. Koefisien regresi variabel iklim sekolah $\left(\mathrm{X}_{1}\right)$ sebesar 0,536 artinya jika nilai iklim sekolah (X1) mengalami kenaikan 1 satuan, maka tingkat kinerja guru (Y) akan mengalami kenaikan sebesar 0,536, dengan asumsi variabel bebas lainya tetap. Koefisien regresi variabel supervisi akademik (X2) sebesar 0,291 artinya jika supervisi akademik $\left(\mathrm{X}_{2}\right)$ mengalami kenaikan 1 satuan, maka kinerja guru (Y) akan mengalami peningkatan sebesar 0,291 dengan asumsi variabel bebas lainya tetap.

Tingkat signifikansi menggunakan $\quad 0,05 \quad(\alpha=\quad 5 \%)$. Berdasarkan tabel 4.19 diperoleh $\mathrm{F}$ hitung sebesar 37,765. Menentukan F tabel dengan menggunakan tingkat keyakinan 95\%, $\alpha=5 \%$ hasil diperoleh untuk F tabel sebesar 3,09.

\section{SIMPULAN}

\section{Pengaruh Iklim Sekolah (X1) \\ dan Supervisi Akademik (X2) Terhadap Kinerja Guru (Y)}

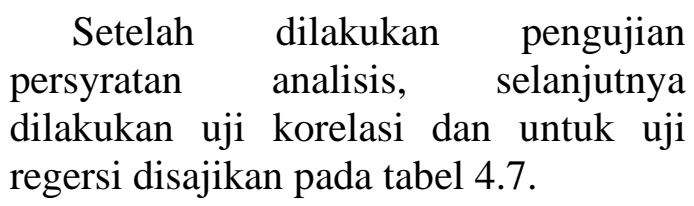
dilakukan uji korelasi dan untuk uji regersi disajikan pada tabel 4.7. 
3. Terdapat pengaruh secara signifikan antara iklim sekolah dan supervisi akademik terhadap kinerja guru Sekolah Dasar Negeri seKecamatan Rumbai Kota Pekanbaru. Besarnya pengaruh yang dihasilkan iklim sekolah dan supervisi akademik secara bersamasama terhadap kinerja guru adalah 48,4\%. Berdasarkan temuan penelitian ini dapat dinyatakan bahwa iklim sekolah dan supervisi akademik berpengaruh secara signifikan terhadap kinerja guru dapat diterima.

\section{SARAN}

Berdasarkan hasil penelitian dan kesimpulan seperti yang dipaparkan sebelumnya, maka pada bagian ini perlu diberikan saran kepada pihak-pihak yang terkait dalam penelitian ini :

1. Bagi kepala sekolah SD Negeri di Kecamatan Rumbai Kota Pekanbaru. Penelitian ini dapat memberikan sumbangan pemikiran bagi pengembangan ilmu administrasi pendidikan, khususnya berkenaan dengan kinerja guru. Mengingat iklim sekolah besar pengaruhnya terhadap peningkatan kualitas kinerja guru, untuk itu setiap kepala sekolah harus bisa menciptakan iklim sekolah yang kondusif agar kinerja guru bisa ditingkatkan.

2. Sebagai bahan kajian untuk mengembangkan pengetahuan tentang pengaruh iklim sekolah dan supervisi akademik terhadap kinerja guru.

3. Bagi penulis, hasil penelitian ini dapat menambah wawasan, pengetahuan dalam melakukan analisis mengenai iklim sekolah dan supervisi akademik terhadap kinerja guru.
4. Bagi sekolah, penelitian ini dapat memberikan masukan penting dalam rangka meningkatkan hasil kerja kepala sekolah dan menambah kemampuan kepala sekolah sebagai bahan pembanding keadaan sekarang maupun yang akan datang. Mengingat iklim sekolah besar pengaruhnya terhadap peningkatan kualitas kinerja guru, untuk itu setiap kepala sekolah harus bisa menciptakan iklim sekolah yang kondusif dan selalu melakukan supervisi akademi terjadwal untuk guru-guru agar kinerjanya dapat meningkat.

5. Bagi peneliti selanjutnya, penelitian ini dapat dijadikan salah satu referensi dalam melakukan kajian terhadap masalah yang sama dan menambah wawasan pengetahuan bagi yang memanfaatkannya. Untuk kesempurnaan dan kelanjutan penelitian ini, peneliti selanjutnya dapat dilakukan dengan lebih memperdalam materi dari masing-masing variabel seperti hubungan sosial diantara guru dan kepala sekolah, situasi kerja untuk meningkatkan mental, komunikasi antar pribadi, konflik, promosi, jabatan, peningkatan kesejahteraan guru, pembagian tugas, dan pola kepemimpinan.

\section{DAFTAR PUSTAKA}

A.A. Anwar Prabu Mangkunegara. (2009). Manajemen Sumber Daya Manusia. Bandung: PT. Remaja Rosdakarya.

\begin{tabular}{|c|c|c|}
\hline Ahmad & Ruky. & (2000). \\
\hline
\end{tabular}

Barnawi dan Muhammad Arifin. (2012). Kinerja Guru 
Profesional. Jakarta: Ar-ruzz media.

Departemen Pendidikan Nasional, (2007). Peraturan Menteri Pendidikan Nasional Nomor 13 / 2007 tanggal 17 April 2007 tentang Standar Kepala Sekolah/Madrasah, Jakarta: BNSP

E. Mulyasa, (2004). Kurikulum Berbasis Kompetensi. Bandung: Remaja Rosdakarya Offset

E. Mulyasa. (2011). Menjadi Guru Profesional. Bandung: Remaja Rosdakarya.

Hamzah B. Uno dan Nina Lamatenggo. (2002). Teori kinerja dan pengukurannya. Jakarta: Bumi Aksara.

Kompri, (2015). Manajemen Pendidikan. Jilid 1, Bandung: Alfabeta.

Mantja, W, (2002). Manajemen Pendidikan dan Supervisi Pengajaran. Malang: Wineka Media

M. Ngalim Purwanto. (2003). Administrasi dan Supervisi Pendidikan. Cetakan kedua belas, Bandung: Remaja Rosdakarya.

Ngalim Purwanto. (2003). Psikologi Pendidikan. Bandung: PT. Remaja Rosdakarya
Sudjana, Nana. (2004). Dasar-dasar Proses Belajar Mengajar. Bandung :Sinar Baru Algensido Offset.

Permendiknas No. 41 Tahun 2007 tentang Standar Proses Untuk Satuan Pendidikan Dasar dan Menengah

Riduwan dan Engkos, (2012). Path Analisis (Analisis Jalur). Bandung : Alfabeta

Robert L Mathis dan Jonh Jackson, (2001). Manajemen Sumber Daya Manusia. Jakarta: Salemba Empat.

Sugiono. (2011). Metode Penelitian Kuantitatif Kualitatif Dan $R \& D . \quad$ Cetakan ke- 14, Bandung: Alfabeta.

Undang Undang Nomor 20 Tahun 2003 tentang Sistem Pendidikan Nasional.

Umiarso dan Wahab, Abd, (2010). Kepemimpinan Pendidikan dan Kecerdasan Spiritual. Jogjakarta: Ar-Ruzz Media.

Wibowo. (2014). Manajemen Kinerja. Cetakan ke-4, Edisi keempat, Jakarta: Raja Grafindo Persada

Wirawan. (2013). Kepemimpinan: Teori, Psikologi, Perilaku, Organisasi, Aplikasi dan Penelitian. Cetakan Ke- 1, Jakarta: Raja Grafido Persada.

Yukl Gary, (2010). Kepemimpinan dalam organisasi edisi ke-5 . Jakarta Barat: PT. Indeks 